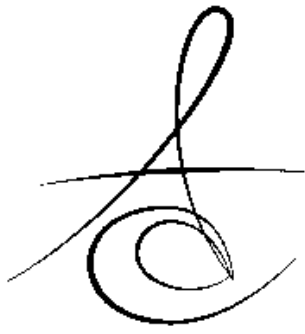

Makale Kodu/Article code: 1792

Makale Gönderilme tarihi: 23.07.2014

Kabul Tarihi: 10.09.2014
KISALTILMIŞ DENTAL ARK KONSEPTİ

\section{SHORTENED DENTAL ARCH CONCEPT}

Prof. Dr. Funda BAYINDIR*

\section{ÖZET}

Diş Hekimliği pratik uygulamalarında eksik dişlerin tamamlanması gerektiği fikri ön plandadır. Bu nedenden dolayı protetik tedaviler klinik uygulamalarda önemli bir yere sahiptir. Bir protetik tedavi yapılırken; protezlerin dental arkla olan uyumu, oral dokular ve Temporo Mandibular Eklem ile olan ilişkisi protezlerin başarısını artırmaktadır. Ayrıca eksik dişlerin tamamlanması hastaları hem estetik hem de fonksiyonel bakımdan tatmin etmektedir. Ancak protetik tedavinin ekonomik veya sosyal nedenlerden dolayı uygulanamadığı durumlarda daha farklı tedavi yöntemleri üzerinde durulmuştur. Bu durumun sonucu olarak da kısaltılmış dental arklar (SDA) protetik diş tedavisine alternatif bir konsept olarak girmiştir ve eksik dişleri bulunan hastalara klasik olarak protez yapımından ziyade konservatif bir takım yaklaşımlar sunmaktadır. Bu derlemede kısaltılmış dental arklar ve çiğneme sistemi ile olan ilişkisi anlatılmıştır.

Anahtar Kelimeler: Kısaltılmış dental ark, çiğneme, oral fonksiyon.

\section{GİRİs}

Hastalar ağızlarındaki eksik dişleri gidermek amacıyla diş hekimlerine başvurduklarında hekimlerden ilk beklentileri estetik ikincisi ise rahat fonksiyon gören bir diş dizisine sahip olabilmektir. Kişinin ağzında yer alan dişlerin sayısı, konumu ve sağlığı yapılacak protetik tedavinin şekline etki eden temel unsurlardır. Diş eksikliğinin konumuna bağlı olarak sabit veya hareketli protez yapılmasına karar verilmektedir. Kısmi dişli ve dişsiz hastalara hizmet sağlayabilmek için diş hekimi oral fonksiyon, vertikal boyut,
ABSTRACT

In the practical application of Dentistry, the idea of completion of missing teeth is in the foreground. For this reason, prosthetic treatments have an important place in clinical practices. While a prosthetic treatment is applied, adaptation of dental arch, relationship with between oral tissues and Temporo Mandibular Joint increase the success of prosthesis. In addition, completion of missing teeth satisfies the patients with the aesthetic and functional maintenance. However, when the prosthetic treatment could not be applied due to economic and social reasons, instead different treatment methods have been developed. As a result of this, shortened dental arches (SDA) have been introduced as an alternative concept to the prosthodonty and offer some conservative approaches instead of conventional prothesis to patients with missing teeth. In this review, the shortened dental arches and its relationship between masticatory system are described.

Key Words: Shortened dental arch, mastication, oral function

okluzyon, sert doku bakımı, TME sağlığı ve hasta konforu gibi faktörleri göz önünde bulundurmalıdır. ${ }^{1}$ Ne tür bir protez yapılacak olursa olsun; protez yapılmadan önce stomatognatik sistemdeki tüm dengeler göz önünde bulundurulmalı ve iyi bir planlama yapıldıktan sonra protez yapımına geçilmelidir. Aksi taktirde hatalı yapılacak bir protez hastanın oral fonksiyonunu, temporomandibular eklemini ve çiğneme etkinliğini olumsuz yönde etkileyecektir.

Hastaların dental arkında bir veya daha fazla eksik diş bulunabilir ve buna bağlı olarak da yapılacak protetik tedavide eksik dişlerin yerlerinin tamam-

*Atatürk Üniversitesi Diş Hekimliği Fakültesi Protetik Diş Tedavisi AD

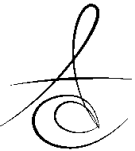


lanması istenir. Klasik olarak uygulanan bu tedavi yöntemine alternatif olarak kısaltılmış dental arklar (SDA) denilen bir konsept ortaya konulmuştur. Kısaltılmış dental ark terimi ilk olarak 1981 yılında Alman prostodontist Arnd Kayser tarafından posterior dişleri kaybolmuş bir dentisyon için kullanılmıştır. Hastaların diş arklarında, geriye kalan diş sayısına ve kısalmanın simetrisine göre Kayser tarafından kısaltılmış dental arkların bir sınıflandırması önerilmiştir. ${ }^{2}$ Kayser tarafından ortaya konulan bu uygulamada hastanın geride kalan dişleri yeni bir dental ark olarak kabul edilmiş ve yeni arkın sınırlarında bir tedavi yapılmıştır.

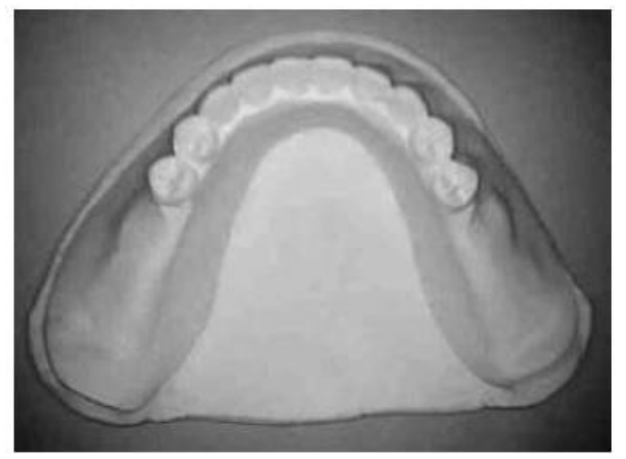

Resim 1. Simetrik Kısaltılmış Dental Ark

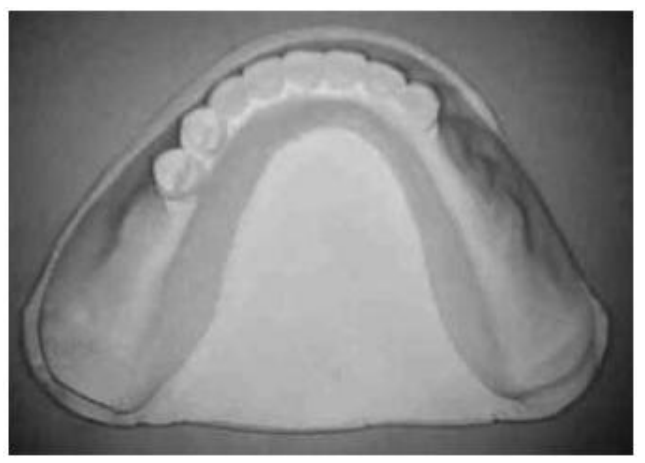

Resim 2. Asimetrik Kısaltılmış Dental Ark

Kısaltılmış dental arklarla ilgili yapılan çalışmalar sonucunda elde edilen bulgular sonucunda anterior ve premolar dişleri içeren diş arklarının fonksiyonel bir dentisyon oluşturduğu yavaş yavaş artan bir görüştür. ${ }^{1,}$ 3-6 Ancak, kısaltılmış dental ark kavramı hala birçok klinisyen tarafından tartışmalı bir konu olarak kabul edilir. Molar dişlerin kaybının çiğneme performansının azalmasına, mandibulada yer değişikliğine ve vücutta çeşitli değişikliklere yol açtığı hayvan deneyleri ile test edilmiştir. ${ }^{7,} 8$ Molar dişler çürük ve periodontal hastalıklara en çok maruz kalan ve ayrıca korunması en pahalıya mal olan dişlerdir. ${ }^{9,} 10$ Hastaların konservatif tedavilere negatif bakış açısı nedeniyle özellikle molar dişler olmak üzere diş çekimi yaygın olarak yapılmaktadır, bu durum da kısaltılmış dental arka sahip bireylerin sayısının artmasına sebep olmaktadır. ${ }^{11}$ Kısaltılmış dental ark çoğu posterior dişin kaybına bağlı olarak daha az okluzal üniteye sahip diş dizisi olarak tanımlanmıştır. ${ }^{12-15}$

Kısaltılmış dental arka sahip bireylerde çiğneme esnasında yük daha az destek diş tarafından karşılanacaktır. Bu durumun sonucunda da hem dişlere hem de Temporo Mandibular Eklem'e (TME) gelen yük artacaktır ve TME'de bir takım değişikliklere yol açabilecektir. Kısaltılmış dental arkların TME değişiklikleri için artan bir risk oluşturduğu da öne sürülmüştür. ${ }^{16,17}$ Kısaltılmış dental arka sahip yetişkin hastalarda TME probleminin prevalansını gösteren az sayıda çalışma vardır. Baran ve ark. ${ }^{18}$ yaptıkları bir çalışmada, TME düzensizliklerine ait semptomların hareketli parsiyel protez kullanan bireylerden çok, diş eksikliği bulunan ancak hareketli parsiyel protez kullanmayan (kısaltılmış dental arka sahip) bireylerde görüldüğünü bildirmişlerdir. Anterior bölgesi tam olan SDA'lı hastalar ile okluzyonda dişleri olan tam dental arka sahip kontrol grubuyla bir karşılaştırma yapılmıştır. Bu çalışmanın sonucu olarak sadece tek taraflı desteği olan ve posterior desteği olmayan hastalarda daha büyük eklem sesi prevalansı görülmüştür. Ancak eklem ağrısı, mandibular mobilite, maksimum ağız açıklığı ve eklem klik sesinde SDA ve kontrol grubu arasında bir fark bulunamamıştır. Kısaltılmış dental arkların TME problemlerine sebep olduğuna dair kesin bir kanıt olmamasına karşın, tek ve çift taraflı posterior destek eksikliğinde ağrı riski ve eklem sesinin arttığı not edilmiştir. ${ }^{19}$

SDA gibi alternatif bir tıbbi uygulama ve tedaviye bakış klasik yöntemlerden tamamen farklı olduğu için değişik toplumlar tarafından farklı şekillerde karşılanmıştır. Kısaltılmış dental ark konsepti büyük bir diş hekimi topluluğu tarafından kabul edilmiş fakat geniş çaplı uygulama yapılmamıştır. ${ }^{20}$ Birçok ülkede diş hekimleri arasında kısaltılmış dental arkların teorik ve pratik kabulü arasında belirgin bir tutarsızlık bulunmaktadır. Konsept genellikle kabul edilmiştir fakat Tanzanya hariç diğer ülkelerde pratikte kullanılmamaktadır. ${ }^{21-24}$ Japonya'da kısaltılmış dental ark 
konseptine karşı şüpheci bir yaklaşım vardır. Japonya ve Almanya gibi gelişmiş ülkelerde eksik dişlerin tedavilerinin yapılması gerektiği düşüncesi benimsenmiştir. Sigorta sistemi düzgün çalışan toplumlar hasta konforunu ön planda tutmuş ve hastalarına en iyi tedavi hizmetini sunmuştur, ancak daha az gelişmiş ülkeler ise ağızdaki mevcut dişlerden maksimum faydalanma yolunu seçmiştir.

2003 yılında yaşlı popülasyonundaki hastaların \%2,7'sinin SDA kriterlerine uygun olduğu tespit edilmiştir. Birleşik Krallık'ta yapılan bir epidemiyolojik araştırma 65 ve 74 yaşları arasındaki bireylerin \%2'sinin kısaltılmış dental arka sahip olduğunu göstermiştir. 1992 yılında Kanada'da, 65 yaş üzerindeki bireylerdeki kısaltılmış dental ark oranı yaklaşık olarak $\% 7,5$ olarak rapor edilmiştir. ${ }^{25}$

1992'de Dünya Sağlık Örgütü (WHO); retansiyon, hayat boyu fonksiyonel, estetik, 20 dişten daha az olmayan ve protez kullanımı gerektirmeyen doğal dentisyonun oral sağlık için amaç olması gerektiğini açıklamıştır. ${ }^{26}$ Kısaltılmış dental ark yaklaşımı, daha az karmaşık, daha az zaman alan, daha ucuz ve daha konservatif bir tedavi alternatifi sunmaktadır. ${ }^{5}$

\section{SDA ve Çiğneme Fonksiyonu}

Çiğneme işleminin gerçekleşmesinde en büyük rolü molar dişler üstlenmektedir. Bu dişlerin bir veya daha fazlasının kaybında çiğneme işleminde birtakım zorluklar meydana gelecektir. Literatürde çiğneme fonksiyonunun diş sayısına bağlı olduğu belirtilmiş ve eğer hastada gelişi güzel dağılmış 20'den az diş varsa çiğneme kabiliyetinin bozulacağı bildirilmiştir. ${ }^{27,} 28$ Yapılan çalışmalar, hastaların posterior diş kaybını, daha fazla çiğneyerek, ${ }^{29}$ daha büyük besin parçaları yutarak ya da daha yumuşak besinleri seçerek karşılayabileceğini göstermiştir. ${ }^{30}$ Bazı araştırmalar distal uzantılı hareketli parsiyel protezin çiğneme verimliliğini artırdığını göstermesine rağmen ${ }^{29,31}$, Gunne'nin ${ }^{30}$ bir araştırmasına göre diyet alışkanlığında büyük değişiklikler beklenmemelidir.

Kısaltılmış dental arkların çiğneme kapasitesi, çiğ havuç gibi kolay absorbe edilebilen besinler çiğneme testlerinde temel alınarak belirlenmiştir. Çiğneme testleri; çiğneme kapasitesi ve okluzal ünitelerin sayısı arasında önemli derecede korelasyon olduğunu göstermiştir. Okluzal ünitelerin sayılarının düşmesiyle beraber, yutkunmadan önceki çiğneme sayısında artışlara intiyaç duyulmaktadır. ${ }^{32}$ Daha güncel bir çalışmada ise, Tanzanyalı kısaltılmış dental arka sahip hastalar ile tam dental arka sahip yetişkinler arasındaki çiğneme becerileri karşılaştırılmıştır. SDA hastaları 0-8 arası posterior dişe ve çeşitli uzunluk ile simetrideki arka sahiptirler. Çiğneme becerisi yaygın tüketilen 20 Tanzanya besininin çiğnenme zorluğuna göre belirlenmiştir. 0-2 çift arası premolara sahip çok kısalmış arka sahip hastalar \%9598 prevelansta çiğneme şikâyetine sahip ve çiğnemede en çok zorluk çeken hastalardır. Buna karşılık premolar bölgesi tam ve en az bir çift okluzyona giren molar dişi olanlarda sadece \%3 ile 5 arasında bir prevelans görülmüştür. ${ }^{28}$ Bu çalışma da, molar dişlerin çiğneme için ne kadar önemli olduğunu gösterir niteliktedir.

Bazı yazarlar; SDA'ı hastalarda diyet değişikliği olmamakla beraber, anterior ve premolar dişlerin varlığında ağızda iyi konumlanmış 20 veya daha fazla dişi olan hastaların yeterli bir çiğneme kapasitesine sahip olduğunu rapor etmişlerdir. ${ }^{33}$ Böylece bozulmuş çiğneme becerisi ya da diyette değişikliklerin sadece okluzyonda 10 dişten az diş bulunması durumunda oluştuğu belirtilmiştir. ${ }^{33}$

Kısaltılmış dental arka sahip hastalarda çiğneme fonksiyonu, besin parçacıklarını öğütmede daha fazla çaba harcadıkları için (yutma'ya kadar daha uzun süre boyunca ve daha yüksek miktarda çiğneme döngüsü) dental arkı tam olan hastalara göre çiğneme fonksiyonu daha az etkilidir. ${ }^{13}$ Orta düzeyde kısaltılmış dental arka sahip hastaların dental arkı tam olan hastalara göre yutma işlemine kadar 1.7 kat daha fazla çiğneme döngüsüne ve 1.6 kat daha fazla çiğneme işlemine ihtiyaç duyulduğu görülmüştür. ${ }^{13}$

Hattori ve ark. ${ }^{15}$ ile Gibbs ve ark. ${ }^{34}$ kısaltılmış dental arka sahip hastaların total maksimum ısırma kuvvetinin tüm dişleri bulunan hastalara kıyasla daha düşük olduğunu belirtmiştir. Benzer sonuçlar Goto ve ark. tarafından da bildirilmiştir. ${ }^{35}$ Fontijn-Tekamp ve ark. ${ }^{36}$ kısaltılmış dental arkı olan hastaların çiğneme becerisinin azalmış kontak alanları nedeniyle tam dişli hastalara göre belirgin şekilde daha düşük olduğunu bildirmiştir. Sarita ve ark. ${ }^{28}$ premolar bölgesi tam olan ve en azından kapanışa gelen bir çift molarların tam dental arka kıyasla yeterli çiğneme becerisi sağladığını belirtmiştir. Khan ve ark. ${ }^{37}$ yaptıkları sistematik bir derleme çalışmasının sonucunda, SDA'nın fonksiyon, hasta memnuniyeti ve maliyet-etkinlik bakımından bir tedavi seçeneği olarak teşvik edilebileceğini öngörmüşlerdir. 


\section{SONUÇ}

Kısaltılmış dental ark konsepti daha konservatif bir tedavi yöntemi olduğundan dolayı stomatognatik sisteme olan fayda ve zararlarını öğrenebilmek için üzerinde daha fazla çalışma yapılması gerekmektedir. Toplumun bazı kesimlerinde iyi bir alternatif tedavi yöntemi olarak kabul edilebilir, ancak günümüz şartlarında modern diş hekimliğinde kendine yer bulması pek mümkün görünmemektedir.

\section{KAYNAKLAR}

1. Armellini D, von Fraunhofer JA. The shortened dental arch: a review of the literature. J Prosthet Dent 2004; 92: 531-5.

2. Kayser AF. Shortened dental arches and oral function. J Oral Rehabil 1981; 8: 457-62.

3. Mohl ND, Zarb GA, G.E. C, Rugh JD. A Textbook of Occlusion. Chicago, IL: Quintessence 1988.

4. World Health Organization Expert Committee. Recent Advences in Oral Health. WHO Technical Report Series. 826:16-17. Geneva: WHO; 1992.

5. Omar R. Reappraising prosthodontic treatment goals for older, partially dentate people: Part II. Case for a sustainable dentition? SADJ, 2004; 59: 228, 230, 232-4

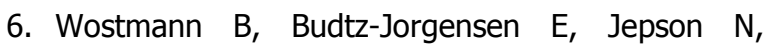
Mushimoto E, Palmqvist S, Sofou A, Owall B. Indications for removable partial dentures: a literature review. Int J Prosthodont 2005; 18: 13945.

7. Chiba A. Effects of molar tooth loss on central nervous system with a behavioral and histological study in mice. J Jpn Prosthodont Soc 1999; 43:299-311.

8. Kobayashi $Y$. The interface of occlusion as a reflection of conflicts within prosthodontics. Int J Prosthodont 2005; 18:302-4.

9. Al-Samadani $\mathrm{KH}$, Ahmad MS. Prevalence of first permanent molar caries in and its relationship to the dental knowledge of 9-12-year olds from jeddah, kingdom of saudi arabia. ISRN Dent 2012; 2012: 391068.

10. Sadeghi M. Prevalence and bilateral occurrence of first permanent molar caries in 12-year-old students. J Dent Res Dent Clin Dent Prospects 2007; 1: 86-92.
11. Kayser AF. Shortened dental arch: a therapeutic concept in reduced dentitions and certain high-risk groups. Int J Periodontics Restorative Dent 1989; 9: 426-49.

12. Gerritsen AE, Witter DJ, Bronkhorst EM, Creugers $\mathrm{NH}$. An observational cohort study on shortened dental arches--clinical course during a period of 27-35 years. Clin Oral Investig 2013; 17: 859-66.

13. Kreulen CM, Witter DJ, Tekamp FA, Slagter AP, Creugers $\mathrm{NH}$. Swallowing threshold parameters of subjects with shortened dental arches. J Dent 2012; 40: 639-43.

14. Maeda Y, Sogo M, Tsutsumi S. Efficacy of a posterior implant support for extra shortened dental arches: a biomechanical model analysis. ] Oral Rehabil 2005; 32: 656-60.

15. Hattori Y, Satoh C, Seki S, Watanabe Y, Ogino Y, Watanabe $M$. Occlusal and TMJ loads in subjects with experimentally shortened dental arches. J Dent Res 2003; 82: 532-6.

16. Luder HU. Factors affecting degeneration in human temporomandibular joints as assessed histologically. Eur J Oral Sci 2002; 110: 106-13.

17. Tallents RH, Macher DJ, Kyrkanides S, Katzberg RW, Moss ME. Prevalence of missing posterior teeth and intraarticular temporomandibular disorders. J Prosthet Dent 2002; 87: 45-50.

18. Baran I, Nalcacı R. Kısalmış dental ark: Oral fonksiyon ve estetik kaygılar açısından değerlendirilmesi, Atatürk Üniv Diş Hek Fak Derg 2007; 17: 13-9

19. Sarita PT, Kreulen CM, Witter D, Creugers NH. Signs and symptoms associated with TMD in adults with shortened dental arches. Int J Prosthodont 2003; 16: 265-70.

20. Kanno T, Carlsson GE. A review of the shortened dental arch concept focusing on the work by the Kayser/Nijmegen group. J Oral Rehabil 2006; 33: 850-62.

21. Witter DJ, Allen PF, Wilson $\mathrm{NH}$, Kayser AF. Dentists' attitudes to the shortened dental arch concept. J Oral Rehabil 1997; 24: 143-7.

22. Allen PF, Witter DF, Wilson NH, Kayser AF. Shortened dental arch therapy: views of consultants in restorative dentistry in the United Kingdom. J Oral Rehabil 1996; 23: 481-5.

23. Allen PF, Witter DJ, Wilson NH. A survey of the

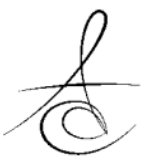


attitudes of members of the European Prosthodontic Association towards the shortened dental arch concept. Eur J Prosthodont Restor Dent 1998; 6: 165-9.

24. Sarita PT, Witter DJ, Kreulen CM, Creugers NH. The shortened dental arch concept--attitudes of dentists in Tanzania. Community Dent Oral Epidemiol 2003; 31: 111-5.

25. Hawkins RJ. The shortened dental arch: prevalence and normative treatment needs in a sample of older Canadian adults. Spec Care Dentist 1998; 18: 247-51.

26. World Health Organization. Recent advences in oral health. WHO Technical Report Series No 826. WHO, Geneva, 1992. p. 16-7.

27. Rosenoer LM, Sheiham A. Dental impacts on daily life and satisfaction with teeth in relation to dental status in adults. J Oral Rehabil 1995; 22: 469-80.

28. Sarita PT, Witter DJ, Kreulen CM, Van't Hof MA, Creugers $\mathrm{NH}$. Chewing ability of subjects with shortened dental arches. Community Dent Oral Epidemiol 2003; 31: 328-34.

29. Chauncey $\mathrm{HH}$, Muench ME, Kapur KK, Wayler $\mathrm{AH}$. The effect of the loss of teeth on diet and nutrition. Int Dent J 1984; 34: 98-104.

30. Gunne HS. The effect of removable partial dentures on mastication and dietary intake. Acta Odontol Scand 1985; 43: 269-78.

31. Witter DJ, Van Elteren $P$, Kayser AF, Van Rossum GM. Oral comfort in shortened dental arches. J Oral Rehabil 1990; 17: 137-43.

32. Aukes JN, Kayser AF, Felling AJ. The subjective experience of mastication in subjects with shortened dental arches. J Oral Rehabil 1988, 15: 321-4.

33. Witter DJ, Cramwinckel AB, van Rossum GM, Kayser AF. Shortened dental arches and masticatory ability. J Dent 1990; 18: 185-9.

34. Gibbs $\mathrm{CH}$, Anusavice $\mathrm{KJ}$, Young HM, Jones JS, Esquivel-Upshaw JF. Maximum clenching force of patients with moderate loss of posterior tooth support: a pilot study. J Prosthet Dent 2002; 88: 498-502.

35. Goto T, Nishinaka H, Kashiwabara T, Nagao K, Ichikawa T. Main occluding area in partially edentulous patients: changes before and after implant treatment. J Oral Rehabi, 2012; 39: 67783.
36. Fontijn-Tekamp FA, Slagter AP, Van Der Bilt A, Van THMA, Witter DJ, Kalk W, Jansen JA. Biting and chewing in overdentures, full dentures, and natural dentitions. J Dent Res 2000; 79: 1519-24.

37. Khan S, Musekiwa A, Chikte UM, Omar R. Differences in functional outcomes for adult patients with prosthodontically-treated and untreated shortened dental arches: a systematic review. PLoS One, 2014, 9: e101143.

\section{Yazışma Adresi}

Arş. Gör. Dt. Alper ÖZDOĞAN

Atatürk Üniversitesi,

Diş Hekimliği Fakültesi,

Protetik Diş Tedavisi AD

Erzurum, Türkiye

Tel.: 044223609 44-1736

e-mail: alprozdgn@gmail.com 